\title{
Temporal Limits on What Engineers Can Plan
}

\author{
Michael Davis ${ }^{1}$ iD
}

Received: 16 March 2019 / Accepted: 22 July 2019 / Published online: 31 July 2019

(c) Springer Nature B.V. 2019

\begin{abstract}
My question is: How far into the future is it possible for engineers as such to plan? For example, the Yucca Mountain Nuclear Waste Repository was to have been designed to store nuclear waste safely for between ten thousand and one million years. Is that the sort of planning engineers as such can do? The planning engineers do would not be philosophically interesting were it not in general so often successful, much more successful than the gambles of ordinary life. So, how is such planning possible — and what are its limits. Is one million years beyond the limits of what engineers, as such, can plan? Is a thousand years? Is a hundred years? Is there an nth generation for what engineers can plan? The answer I consider here is that engineers can plan only as far into the future as they can reasonably expect engineers to be present. That is only a few generations at most.
\end{abstract}

Keywords Engineer · Discipline · Planning · Yucca Mountain · Great Pyramid

Kyoto University recently held a conference entitled "Science, Technology, and Future Generations." 1 Despite the title, the conference included little about the relationship between future generations and science or technology. This commentary will not directly address that relationship either. Instead, it will address a narrower question: How far into the future is it possible for engineers as such to plan? Since engineers do much of the planning humans now do, especially large-scale planning, such as power grids and road systems, answering that narrower question might help regional planners, economists, politicians, and the like answer the broader question,

\footnotetext{
${ }^{1}$ 11th International Conference on Applied Ethics, "Science, Technology, and Future Generations," Center for Applied Philosophy and Ethics, Graduate School of Letters, Kyoto University, Kyoto, Japan, December 15-16, 2018. An earlier version of this commentary was presented there. Thanks to those in the audience for several useful comments. Thanks also to three of this journal's reviewers for their detailed suggestions.
}

Michael Davis

davism@iit.edu

1 Humanities Department, Center for the Study of Ethics in the Professions, Illinois Institute of Technology, 5300 South Shore Drive \#57, Chicago, IL 60616, USA 
"How is successful large-scale planning possible, when it is, whether or not engineers do it?" This commentary will conclude with a few words about what sort of planning engineers should not do.

\section{Introduction}

The temporal limits of engineers' planning is an important topic for engineers. Engineers are increasingly concerned with "life-cycle planning" and "sustainable development." Life-cycle planning is a guide for treating an artifact (or process) that begins with its conception and ends when the artifact has ceased to have a distinct existence-which can, in practice, be quite far in the future. The Code of Ethics of the National Society of Professional Engineers (NSPE) gives a definition of "sustainable development" that engineers seem generally to accept:

the challenge of meeting human needs for natural resources, industrial products, energy, food, transportation, shelter, and effective waste management while conserving and protecting environmental quality and the natural resource base essential for future development. (NSPE 2007n.) ${ }^{2}$

For more than a decade now, the NSPE Code has encouraged engineers to "adhere to the principles of sustainable development in order to protect the environment for future generations" (NSPE Code 2007, III.2.d). The Code does not set a limit to the number of future generations whose environment is to be protected.

Statements about the present or past are, if meaningful, either true or false; statements about the future are not. Statements about the future merely become true or false depending on what happens (or, at least, that is what this commentary will assume). There is no knowledge of the future-or, at least, not the detailed and useful knowledge available for past or present. At best, what those who plan the future have instead of knowledge of it are mere probabilities.

Yet, engineers do plan as part of their work and many, especially civil engineers, plan for decades, and a few for even longer. For example, starting four decades ago, engineers helped to design the Yucca Mountain Nuclear Waste Repository to store highly radioactive nuclear waste safely in the Nevada desert for at least 10,000 years. $^{3}$ The Repository was a big project. By the time it was abandoned in 2011 , it had cost $\$ 9$ billion. If completed, it would have had 40 miles of tunnels and stored 77,000 metric tons of nuclear waste deep underground. ${ }^{4}$ The project was

\footnotetext{
2 There are, of course, other definitions of "sustainable development," including some that make explicit mention of "social justice," but engineers do not seem ready to embrace them.

3 The design criterion for Repository should have been one million years, not 10,000, because the deadly radiation coming from the waste would not have degraded to something like the environment's natural background radiation until about a million years. At 10,000 years, the nuclear waste would still be "hot" enough to constitute a serious health hazard to nearby humans or animals. 10,000 years seems to have been a compromise, making the design problem easier (Wikipedia 2019c).

4 Ratliff (1997), Endres (2009), and Wikipedia (2019c). The Finns are now building a similar repository at Onkalo. For details, see Wikipedia (2019b). The argument made here seems to apply to the Onkalo repository as well. Thanks to Hidekazu Kanemitsu for calling attention to what the Finns are doing.
} 
abandoned after Congress ended funding. Congress seems to have ended funding for political reasons, especially an unhappy Senator from Nevada, not for the technical or ethical reasons considered here. Recently, there has been an effort in Congress to restart the project (Wikipedia 2019d; YuccaMountain.org 2019). The Repository is not merely of historical interest.

Making plans for such large-scale, long-term storage may seem more like science fiction than like engineering, especially to engineers, but the planning that engineers do is philosophically interesting precisely because it is so often both fantastic and successful, successful much more often than the experiments of science or the "sure things" of ordinary life seem to be. So, one might reasonably ask how such planning is possible - and what its limits are. Is a 100 years beyond the limits of what engineers as such can plan? Is a thousand years? Is 10,000 years? Is there a time beyond which engineers as such cannot plan? Is there a time beyond which they should not plan?

These questions belong to the philosophy of technology insofar as engineers help to create, operate, and dispose of technology (that is, systems of skills, methods, artifacts, and processes by which humans produce the goods and services that make their life possible, comfortable, or enjoyable). But these questions also belong to the philosophy of professions insofar as engineering is a profession and one profession may have technical standards distinct not only from the public's as such but also from those of other professions. What may be within the competence of one profession may not be within the competence of another. So, for example, dentists are not competent to design punch presses nor are engineers competent to do root canals; and, of course, most people are not competent to do either.

\section{Refining the Question}

So, the question has become how far into the future engineers as such can plan. The answer to be considered here is that engineers as such can at most plan only a little farther into the future than they can reasonably expect engineers of the right sort to be present (two or three generations). Beyond that time, engineers can still plan, perhaps even successfully, but not as engineers. Thus, this commentary will not focus on the empirical question, How far into the future can humans called "engineers" plan? No doubt, people called "engineers" can plan as far into the future as they wish. Consider the ancient tomb known as "the Great Pyramid at Giza." It was the tallest building in the world from about 2560 BC until the spire of England's Lincoln Cathedral overtopped it just after 1300 AD. Suppose the Great Pyramid's designers had been called "engineers." They could have planned the Pyramid to serve a certain purpose forever, or for 10,000 years, or for just a few 100 years. The Great Pyramid is now more than 4500 years old. It might still be serving its original purpose had robbers not broken into it long ago, removing the artifacts it was designed to hold safe. Whatever the rate of failure for human planning on the Great Pyramid's scale, humans can, it seems, plan a building that could serve its purpose for thousands of years, as the Great Pyramid could have (but did not). 
But was what the ancient Egyptians did when they built the Great Pyramid engineering rather than some other sort of building? Should we count as engineers the "builders" of the Great Pyramid, that is, those who designed the Pyramid or managed its construction? There are at least three reasons not to count those builders as engineers.

First, and least important, the Great Pyramid is a tomb. Typically, engineers do not build tombs. Building tombs seems to have been, and remains, primarily the work of architects, stonemasons, artists, and the like. Engineers are brought in only if the tomb requires construction methods that only engineers can safely or reliably use. Claiming that ancient engineers built tombs thus raises the question of how one is to distinguish between engineers strictly so called and architects, stonemasons, artists, and other tomb builders, however called, who are similar to engineers insofar as they build on a large scale, use sophisticated methods, and so on. That is an important question to which this commentary will return.

The second reason to deny that any builder of the Great Pyramid was an engineer is that engineers, engineers strictly so called, would probably not have designed a tomb in the way Egypt's ancient builders did. For example, there is no practical reason for the Great Pyramid to be as large as it is. A smaller pyramid could have served the same purpose more economically-as later pyramids did. Indeed, so could a less conspicuous underground tomb.

The point now is not that the government of ancient Egypt did something unwise or morally wrong when it built the Great Pyramid. That is a subject for political philosophy. The point now is that the engineers of ancient Egypt (assuming there were any) would seem to have done something engineers should not have done, that is, wasted their employer's resources. Whether they ("the ancient Egyptian engineers") did something they should not have done depends in part on what "engineer" means in the assertion that there were (or were not) engineers in ancient Egypt to do it.

Third, the meaning of "engineer" relied on here is not a dictionary definition or a classical "abstract" or "verbal" definition-genus and species, necessary and sufficient conditions, or the like. The meaning is, instead, a living practice, a number of human beings organized in a certain way, the profession of engineering. This sort of definition resembles what mathematicians call "recursive" or "inductive" definition. It chiefly differs from the mathematical analogue in being "practical," that is, part of the practice of engineering, not merely an activity a scholar might perform on her own. The first step is that a certain number of people recognize themselves and each other as engineers, that is, as belonging to the same discipline (a distinctive way of doing certain things). The next step is to have those people examine the credentials of the next candidate for admission, accepting (or rejecting) him or her as competent to do what they do. If accepted, the new member of the set joins in the evaluation of the next candidate. And so on. (For more on this, see Davis 2009.)

Like anyone else, a philosopher can advise engineers concerning who is or is not an engineer (strictly so called), but the decision belongs to the profession much as (authoritative) decisions about what the law is belong to judges, though anyone may offer an opinion. The claim made here - that the builders of the Great Pyramid were not engineers-relies on the standards that the profession of engineering uses to identify engineers today (engineers strictly so called). 
Sometimes applying those standards is easy, for example, when the candidate engineer is a recent graduate of a law school with an undergraduate degree in literature. Such a candidate is, all else equal, certainly not an engineer. In contrast, the graduate of an accredited program in mechanical engineering with 5 years' experience working as mechanical engineers typically work certainly is. Sometimes, however, the decision is harder to make, for example, when a chemist has been in responsible charge of a chemical plant for more than a decade: should engineers treat her as one of them?

This definition does not, please note, claim to cover all those individuals, and only those individuals, called "engineers." There are engineers strictly so called who are not called "engineers," for example, naval architects. There are also people legitimately called "engineers" who are not engineers strictly so called, for example, those technicians who, like Casey Jones, drive locomotives or, like the janitor of a high-rise building, are licensed to operate the boilers that heat the building but have only a high-school education. Who is properly called "engineer" has only a loose connection with who is an engineer strictly so called.

This definition also did not define engineers by what they do (some special function). That is because engineers do many things: design, inspect, test, manage, teach, write manuals, testify in court, lead tours, and so on. They perform those functions not merely by chance but because their training prepares them to, because they regularly offer to perform those functions, and because their employers regularly accept the offer. Of course, the designs that engineers typically prepare are engineering designs, not any sort of design; the inspections they typically perform are engineering inspections, not any sort of inspection; and so on.

The definition just sketched identifies engineers (strictly so called) using a certain practice, the profession of engineering. A profession is, in part at least, a shared discipline, a certain way of doing certain things that the members of the profession, and only its members, share. The discipline is passed from one generation of engineers to the next by a curriculum that engineers typically follow and non-engineers typically do not. The reason engineers recognize naval architecture as engineering (whatever naval architecture is called) while they do not so recognize ordinary architecture (however similar ordinary architecture is to engineering in function), is that naval architecture shares a discipline with the rest of engineering that ordinary architecture does not. Engineers have only to look at the curriculum of naval architects to see that naval architecture is engineering, not architecture, and that the graduates of that curriculum will not be architects but engineers —or, at least, in need of only a few years of engineering experience to become engineers rather than mere "engineers in training" (Davis 2010a). The reason other disciplines similar to engineering in name and function-genetic engineering, geo-engineering, climate-engineering, and the like-are not engineering (despite the name) is that they do not share the appropriate discipline. In each case, the core curriculum differs from engineering's in ways engineers typically consider important.

The exact structure of engineering's discipline is a matter of history, not logic. Engineering might have had a somewhat different curriculum, one allowing industrial chemistry or software engineering to be a part of engineering (as chemical engineering and computer engineering are). Indeed, probably nothing much but 
decisions of the professions in question prevents some such amalgamation from occurring tomorrow. What logic forbids is that engineering should absorb industrial chemistry or software engineering without some change in at least one of the disciplines. Disciplines are as real as nations, political parties, languages, or business corporations - and, like them, distinct historical individuals. They can change, but the change involves complex social practices, not just words. The price of change ("the transaction costs") can be high. Philosophers must take that into account if they are to understand what engineering is and why it is not many things logic says it could be.

There are, of course, verbal definitions of engineering useful in practice. Perhaps the best known comes from ABET (the body, formerly known as "the Accreditation Board of Engineering and Technology," that accredits programs for educating engineers in the US and many other countries):

Engineering is the profession in which a knowledge of the mathematical and natural sciences gained by study, experience, and practice is applied with judgment to develop ways to utilize economically the materials and forces of nature for the benefit of mankind. ${ }^{5}$

However useful and authoritative this definition is in practice, it is not a good philosophical definition of engineering. It fits architecture, industrial chemistry, industrial design, and even carpentry as well. ${ }^{6}$ Architects, for example, also use their knowledge of mathematics and natural science, with judgment, to take advantage of materials and the forces of nature, to build structures economically for human benefit. Architects just differ enough from engineers in the mathematics and natural science they learn, the sort of judgment they exercise, and the way in which they seek to benefit humanity for (most) engineers to refuse to recognize them as sharing their discipline.

The discipline of engineering is not static, of course. Even some respected engineers of the past might have trouble gaining entry into the profession if, being reborn or revived with their knowledge, skill, and judgment intact, they asked to join today. Some engineers of the past lacked important skills or ethical commitments today's engineers think important. Whether those engineers of the past should count as engineers, nonetheless, is a different question, one hard to answer in part at least because it has no practical significance. It is a question best left to historians, philosophers, and the like.

One conclusion that does follow from the definition of engineering presented here is that there are likely to be changes in engineering's discipline even in the next few years - and so, in who counts as an engineer (strictly so called). But the details of those changes are hard to predict. For example, no one today should claim to

\footnotetext{
5 Western Michigan University, 2018. There are a lot of references to this definition on the web, all crediting ABET, but it does not seem to be on ABET's website.

6 That is, if carpentry is a profession. Carpentry certainly is a profession if "profession" just means lawful occupation (which might be all that ABET means here). If, however, "profession" includes other features, such as college education or high social status, carpentry is not a profession.
} 
know the answer to such questions as these: Will engineering programs reduce the calculus required from two years to one? Will they allow the substitution of biology for physics? Will they require a course in statistics?

Is it possible for engineers to appear in history more than once, say, in the Buddhist monasteries of eighth-century China as well as in the French army of the seventeenth century? To ask that question is similar to asking whether it is possible for George Washington to appear in history more than once. The answer depends on how "thick" the description of the individual in question is: the thicker the description of the individual, the less likely that history can repeat itself. So, for example, if the description includes many details of Washington's life (for example, that he commanded the American army during the Battle of Monmouth or that he wore false teeth much of his life), history cannot repeat itself. The specific details are themselves historical individuals tied to a distinct time and place (the weather, the battles that came before, the weapons available at that time, and so on). Since the definition of engineering offered here is quite thick, it is unlikely that engineering so defined will appear in history more than once.

Consider again the possibility of "ancient Egyptian engineers." The engineering curriculum did not begin in ancient Egypt. The chain of teachers and students that constitutes the profession of engineering reaches from today back to the French military of the late 1600 s. For a few centuries before then there were soldiers, stonemasons, inventors, and even artists sometimes called "engineers," but no engineers strictly so called, and certainly no school to train them in an identifiable discipline. Given the definition of engineering presented here, there is no reason to count any of the builders of ancient Egypt as engineers (strictly so called).

So, the question this commentary is to address has become, What is it possible for engineers (strictly so called) to plan while remaining within their discipline? Outside their discipline, engineers are like everyone else, individuals with knowledge, skill, and ambition. They can plan anything they like, but they are much less likely to succeed than engineers typically do. What they do will not be engineering.

\section{How Engineers as Such Plan}

What then is known about how engineers as such will plan? One thing that is known is that there is a high probability that engineers will preserve continuity between current and future practice (safety factors, standards of reliability, permissible tolerances, and so on). There are at least two reasons that such continuity is highly probable.

First, the engineering curriculum will not change radically over the next century or two because, if it did, it would cease to be an engineering curriculum. Radical change would signal a new discipline. Change in engineering's curriculum must, then, remain within certain limits, however hard it may be to specify those limits exactly. This is a conceptual truth, not an empirical one. There is an analogy here with language. A language can change much over time while remaining the same language, as English has since, say, 1600. Today's native speakers of English in Scotland, New Zealand, or Jamaica can still read the works of William Shakespeare 
or Sir Francis Bacon, though they would not write that way (except to imitate). But too radical a change, say, from Old English (Anglo-Saxon) to Modern English, creates a new language, not just a variation on the old. Changed that much, there would be two mutually incomprehensible ways of talking or writing. Only scholars can read Beowulf in the original Old English. Differences in degree can become differences in kind.

Second, there is good reason to believe that engineering practice will not change much over the next century or two because continuity is (currently) part of engineering's discipline. For example, assuming that there are engineers a hundred or even 200 years from now, there is good reason to believe that they will generally continue to document what they do much as engineers do now, preserve those documents, and use the information the documents contain when called into repair, improve, or replace a particular bit of engineering. There is good reason to believe that documentation will continue to have the central place in engineering that it now has even though documentation is a mere fact about engineering, not a necessary part of it. Engineers typically require a good reason to change the way they work (since, all else equal, change is an expense). Documentation reduces duplication of effort, allowing one engineer to pick up where another engineer left off (rather than having to "re-invent the wheel"). Documentation is likely to be at least as useful to future engineers as it is to today's and unlikely to hinder good engineering in any way.

The change engineers prefer is incremental, for example, ever more precision in their documents. They do not like to go far outside their "data base." When they do introduce a new artifact (or process) into the world, they typically do it in stages, moving from laboratory tests to pilots, from pilots to field tests, and from field tests to ordinary use. Even after an artifact has entered ordinary use, engineers typically continue to monitor it. They do that not only so that they can fix problems as they appear but also so that they can make positive improvements as they see the opportunity. This permanent search for problems and opportunities seems to explain much of engineering's success. Engineering artifacts do not go into the world naked; instead, they go into the world armored in an enduring process that identifies problems, recommends solutions, and sees that the solutions are carried out.

Of course, the world may change faster than engineering. For example, robots may replace engineers in such jobs as inspection, scheduling routine maintenance, and the like. Such change may cause the number of engineering jobs to decrease substantially, leaving many engineers unemployed and in search of new ways to be employed. But such change could nonetheless leave the remaining engineers not much different from today's, except that the work they do would have to be more creative, the kind of engineering that robots, even robots with great intelligence, cannot do. That is not to claim that engineering will not someday disappear altogether. Disciplines come and go. Where are the alchemists, alienists, apothecaries, conveyancers, and the like of yesteryear? The only claim made here is that, while engineering continues to exist, the way engineers work will only change slowly. The $n e x t$ generation of engineers will resemble today's much more than they will differ. 


\section{The Useful Life of an Artifact (or Process)}

Asked how long the artifact (or process) they are designing will last, engineers typically answer a slightly different question. They answer with the artifact's "probable useful life." The useful life of an artifact is generally determined by the technology around it, both by what the artifact has to compete with and the cost of repair, especially the cost of replacement parts. So, for example, automobiles that are a hundred or even a hundred-fifty years old exist and can be operated, but their useful life is over. They are "museum pieces" or "collector's items," vehicles that no longer meet minimum road standards (such as for tailpipe emission or crash safety). They are also too expensive to repair for ordinary use (in part because many replacement parts must be handmade, the mass market for those parts having disappeared long ago).

The oldest engineering artifacts, those that have had a useful life of a hundredfifty years or so-a few aqueducts, bridges, canals, dykes, railway lines, sewers, and so on-have had to be updated in various ways to survive alongside newer technologies. So, for example, the traffic lanes of the Brooklyn Bridge were originally designed for the horse-drawn carriages and rail traffic of the late nineteenth century. They had to be reconfigured for automobiles. Without that reconfiguration, the Brooklyn Bridge would today probably exist only in the way the Iron Bridge over the Severn does, that is, as part of a museum, not as an artifact in ordinary use.

The longest lasting artifacts of engineering also require regular maintenance to continue their useful life. Thus, the steel cables that support the great spans of the Brooklyn Bridge must be cleaned and painted every few years to prevent rusting. Without that maintenance, the Bridge would likely have become unsafe long ago. Like most, perhaps all, works of engineering, the Brooklyn Bridge was not designed to last for long without humans to maintain it, especially engineers to carry out routine inspections and oversee the maintenance. No doubt, the history of engineering explains why the works of engineers, unlike the Great Pyramid, require so much maintenance. But, whatever the explanation, that need should not be forgotten here.

\section{How Far into the Future Can Engineers as Such Plan?}

With that, this commentary returns to the Yucca Mountain Nuclear Waste Repository. The discipline of engineering goes back less than four centuries. In that time until the Repository, engineers have never, it seems, tried to build an artifact with a probable useful life of even a few centuries, much less one with a probable useful life of 10,000 years. Planning for 10,000 years is well beyond the experience of engineers (the profession as a whole, not just individual engineers). When working beyond their experience, engineers prefer to scale up slowly. For engineers, even scaling up from a few decades to a few centuries would be an unprecedented leap into the unknown.

That is not the only concern engineers should have about participating in the Yucca Mountain Repository. Planning for an artifact with a useful life of even a 
few centuries seems to require social planning of a sort foreign to engineering. For example, to ensure that there will be suitably trained engineers even two centuries from now seems to require arrangements that will guarantee the existence of similar engineers for all the years between now and then, engineers trained to manage, inspect, repair, and update such a repository, to keep appropriate records for use by the engineers who follow, and so on. Training those engineers would seem to require at least one school of engineering to teach the requisite discipline, a school the endowment and other resources of which would not run out in less than two centuries. Such a school must have enough students every year to sustain at least one "professor of repository science" (someone who can pass on the special knowledge, skill, and judgment that only an engineer familiar with the Repository or repositories like it would have-including their "tacit know-how"). The school would also require enough employers to hire enough graduates of the school to make potential students think repository engineering an attractive career. ${ }^{7}$ Engineers have never been trained to do that sort of social planning.

The point now is not that humans cannot engage in such planning. They can. For example, a large church might have enough maintenance to do annually to keep a few stonemasons busy indefinitely. As the centuries pass, changing styles of stonework, the church would have to choose between maintaining its original style and modernizing. If the church chose to retain its original style, its masons would in time become distinct from stonemasons generally. They would have to become a specialized guild, training "old style masons" for its employer's building (and ones like it) rather than "modern masons" of the sort the rest of the world would ask for.

Note that this specialization presupposes enough work to keep the old-style masons working more or less continuously. Without enough work, the old-style masons could not keep up their "old style." They would have to find other work just to live, leaving the church no choice but to hire modern masons the next time it needed masons. Not working as the old-style masons did, the modern masons would not produce the results the old-style masons did (not at all or, at least, not as efficiently).

It is, then, probably a mistake to bet that the future will include engineers qualified to design social institutions to manage, repair, and update the Repository for 200 years, much less for 10,000. The Repository was not designed to require many engineers once it was filled and sealed. Every year old engineers die or retire and new ones, those without the experience of the old ones, replace them. One or two generations of ordinary operation once the Repository is full would probably be enough to drain the pool of those with the special knowledge, skill, and judgment of the original "repository engineers"; the same for "engineers" trained to design, maintain, and improve the social institutions to prepare the next generation of

\footnotetext{
7 That perhaps is why so many of the surviving programs in nuclear engineering now focus on medical uses of radioactive materials, updating existing nuclear power plants, disposal of nuclear waste, and so on. The jobs are no longer many jobs in design or construction of new nuclear power stations. If there ever are again, programs in design and construction may have trouble finding suitably qualified engineers.
} 
repository engineers. A better bet for engineers than trying to design institutions to support the Repository over even 200 years may be to design the Repository in such a way that most futures (those without engineers as well as those with them) could manage, update, and repair the Repository indefinitely. The simpler the design, the more likely that the future that happens will have the resources to manage, update, and repair the Repository. But the simpler the Repository's design, the less likely that the Repository will need engineers to plan or build it, much less to maintain it. The technology of the most resilient Repository might well resemble the technology of the Great Pyramid more than the technology of anything that engineers have built. After all, the Repository is, in principle, a tomb, the simplest form of which would be a mere hole in the ground filled with canisters of nuclear waste and topped with earth, the holes laid out in rows like graves at a military cemetery.

The chief risk to the useful life of such a simple repository is probably the modern equivalent of the "tomb robbers" who ended the useful life of most of Egypt's pyramids, that is, those enterprising individuals or gangs who find a market for the repository's canisters or nuclear waste. Human guards are the chief way to protect against such robbers (supported these days by cameras, motion detectors, and other "security devices"). But there will probably still be some need for engineers (or some similar discipline) to inspect the holes now and then to check for leakage that might enter the water table or air-and to figure out what to do if a hole begins to leak. However sure the scientists are about the materials holding the waste, the hydrology under the holes, the geology around the holes, and the future climate, engineers will want at least one backup for whatever seems a safe way to store waste (a safety factor). Scientists are constantly discovering that the world is more complicated than they thought. Human inspection is the ultimate backup, using qualified engineers when available and something like rent-a-cops when not.

The argument so far seems to have produced a dilemma. To plan for the distant future, even for a few centuries from now, engineers must either a) do, or at least assume, a good deal of social planning, enough to guarantee that there will be engineers competent to tend the complex artifact in question for its desired useful life (at least a few centuries), or b) design the artifact so that it is simple enough to survive any plausible change in social organization during its desired useful life, even a collapse of civilization that would leave no engineers competent to maintain, repair, or update the artifact. Neither horn of the dilemma seems to belong to the discipline of engineering in its current form-nor in a form that it is likely to take any time soon.

\section{How Far into the Future Should Engineers as Such Plan}

The conclusion, then, seems to be that the future for which engineers as such can plan is quite near, perhaps no more than two or three generations away, the time for which it seems reasonable to assume that there will be both engineers of the right kind and the appropriate supporting technology.

Engineers might respond in one of two ways to this substantial limit on what they can do as engineers. First, they might just shrug and say, "If you want to plan for more than two or three generations, hire a futurist or some other technologist, not an 
engineer. What we do, we do well. But planning for more than a few generations is not among the things we do." Second, engineers might respond instead, "We need to revise the engineering curriculum so that engineers of the future will be competent to plan for many more generations than engineers are today. In particular, we need to include a good deal of 'social engineering' in our curriculum." 8

What engineers as such cannot answer is that they should just muddle through, trying to do whatever their employer asks of them. Their "paramount" responsibility is to "the public health, safety, and welfare," not to their employer. (See, for example, NSPE 2007, I.1.) Of course, as a matter of fact, some engineers might decide just to muddle through — whether to keep their job, or out of loyalty to their employer, or even because they just believe that engineers can solve any problem given them. But they cannot, as engineers strictly so called, just try to muddle through. They must adhere to their discipline. Just muddling through, they would have become engineers in name only, no more to be relied on than the scientists, managers, programmers, and the like whom they are typically brought in to augment.

For now, then, engineers have an ethical problem whenever asked to plan for more than two or three generations. Most codes of engineering ethics require engineers to perform services only in areas of their competence. (See, for example, NSPE 2007, I.2.) Engineers as such are not now competent to plan for more than two or three generations. So, it seems, today's engineers should refuse to work on a project like the Yucca Mountain Nuclear Waste Repository; or, if they do work on it, they should limit their part in the work to what both they and their employer would count as success even if the actual useful life of the resulting artifact were no more than two or three generations, for example, a repository designed to keep nuclear waste safely for two or three generations, until a better solution calls for the waste's retrieval. Engineers should leave planning for later futures to futurists or other technologists, whether such technologists exist now or not. While society has a responsibility to find a way safely to dispose of nuclear waste or store it safely for at least 10,000 years, an engineer as such only has a responsibility to do as society asks when that is within the engineer's competence (ethical as well as technical).

Most codes of engineering ethics also require engineers to "advise their clients or employers when they believe a project will not be successful." (NSPE 2007, III.1.b.) Like almost any construction designed to produce an artifact with a useful life of several centuries, much less 10,000 years, the Yucca Mountain Repository is probably something that engineers cannot, as engineers, believe could be a successful engineering project. There is no precedent for engineers producing an artifact having a useful life of even two centuries. There are, of course, a few religious buildings, such as the Monastery of Paromeos in Egypt or the Izumo-taisha Shrine in Japan, that have been in continuous use for more than a 1000 years (Wikipedia

\footnotetext{
8 While including some social engineering in tomorrow's curriculum may seem a good idea, engineers have yet to invent a way to do that likely to be useful. A little training in social engineering may not be much better than none; enough training in social engineering to be useful may turn out to demand a curriculum as distinct from engineering's as that of computer science or operations management now is. The resulting "social engineers" would, then, not be engineers strictly so called, however useful they might be.
} 
2019a, c). But no one has ever built a substantial structure with a useful life of more than a few 1000 years - and those with that long a useful life catered only to the simple needs of the dead.

That being so, engineers asked to work on a project such as the Yucca Mountain Repository should tell their employer that they do not believe that it would be successful. Indeed, they should refuse to work on such a project because it exceeds their competence. They may, of course, suggest alternatives within their competence, for example, tombs for nuclear waste likely to be safe for at least two or three generations. Any such repository should also include inspection, repair, and updating, because engineering artifacts typically have a short useful life otherwise.

Perhaps this is an appropriate place to make a distinction between micro-ethics, macro-ethics, and meso-ethics to clarify what sort of argument is being made here. Micro-ethics is another name for ordinary morality, the standards a mere individual should bring to any decision (and the practices by which those standards should be applied, the answers that should result, and the like). Macro-ethics are the standards governments should bring to questions of social policy (for example, whether to build the Yucca Mountain Repository). Meso-ethics are the standards that voluntary organizations, such as professions, should bring to the decisions they makewhether the decision-maker is a single member of the profession, a team, a professional society, or the profession as a whole. To act as an engineer (strictly so called) is never to act as a mere individual but as a member of a cooperative association (the engineering profession). What is morally right for an engineer may differ both from what is morally right for government and what it is morally right for a mere individual to do. So, for example, though both governments and individuals may properly design, establish, or operate primary schools or mental health clinics, engineers as such should not (Davis, 2010b).

\section{Planning in General}

That leaves the question the commentary initially put aside: how is useful planning for the future possible (possible for anyone, not just engineers)? We may divide that question into at least three subsidiary questions-with somewhat different answers. The first subsidiary question concerns the "near future," say, the next 5 or 10 years. Planning for that future is, it seems, not hard because it is (more or less) for an extended present. It is probable (but not certain) that not much will change in so short a time.

The second subsidiary question concerns the "middle future," whatever is beyond the near future but not yet the "distant future," say, from 10 years up to two or three generations. Planning for the middle future is harder than planning for the near future because more will probably change in unpredicted ways, with the probability (and magnitude) of unpredicted change increasing geometrically the farther into the future the planning tries to go. About all that is probable for the middle future is that what the NSPE Code of Ethics calls "environmental quality and the natural resource base essential for future development" will not change much. Humans will continue to need clean air, clean water, sources of energy, a moderate climate, shelter, and so 
on. Planning for the middle future may, then, consist in large part in "conserving and protecting" environmental quality and natural resources. Even so, planning for the middle future does not seem to be the kind of planning that should be done today and never again. Successful planning for the middle future seems to require regularly revising the plan in response to unpredicted change ("mid-course corrections"). This is a kind of planning that many people do successfully, not only engineers but also architects, economists, politicians, and the like. Of course, who should work on this or that plan depends on the sort of plan it is.

The third subsidiary question concerns the "far future," the time from the end of the middle future until the end of time. When planning for the far future, all that humans, engineers or not, can be reasonably sure of is that that fure will probably differ from today in many unpredicted ways, some quite important for planners. There are many causes of unpredicted change, from earthquakes to asteroids, but perhaps the most likely and important is human inventiveness, not only the inventiveness of engineers, architects, economists, and politicians, but also of biologists, business managers, investors, lawyers, musicians, and so on. Anyone who claims to know much about the far future, even just its needs or resources, will probably turn out to be mistaken on many important points. For example: What futurist of 1820 would have guessed that just two centuries later, humans would need the vast quantities of coal, petroleum, methane, nuclear energy, and the like now used? Or that half the world would live in cities? Or that plastics would pollute the oceans? There is not yet a discipline with much success predicting the far future, much less successfully planning for it. Most predictions consist of projecting current trends into the future, not anticipating inventions that inaugurate new trends. That, perhaps, is why not much ages faster than science fiction.

\section{Concluding Remarks}

One conclusion that may seem to follow from what has been said so far is that engineers should have objected to designing, building, or overseeing nuclear power plants when that source of electricity was first proposed seventy or so years ago. Much of nuclear power, especially the disposal of its waste, was then well outside engineering's "data base." There are, however, at least five reasons to doubt this conclusion.

First, 70 years ago engineers did not typically do life-cycle analysis of the artifacts (or processes) they designed. Without such an analysis, they would have had much less reason to object to nuclear power than they do today. Life-cycle analysis has given engineers information they once lacked, alerting them to problems they used to miss. Life-cycle analysis has changed "the state of the art" for engineers.

Second, the chief ground for engineers to object to nuclear power 70 years ago would have had to have been the "public health, safety, and welfare." But the profession did not then agree that "the public" included future generations. Indeed, one reason for the recent addition of "the environment" and "sustainable development" to codes of engineering ethics seems to have been to protect future generations because the earlier references to "the public" arguably did not. Engineering 
ethics (the special morally permissible standards of conduct that govern engineers just because they are engineers) is not static.

Third, another reason that codes of engineering ethics now include references to "the environment" and "sustainable development" may be that engineers realized that they lacked enough guidance on how to balance the current public's need for polluting resources, such as coal, petroleum, and methane, against the competing need for clean air, clean water, healthy forests, and so on. Energy both contributes to human welfare, because it helps to raise the standard of living, and damages that welfare, because production of energy tends to pollute the air and water, destroy forests, and so on. Furthermore, there is a question of justice here. The distribution of benefits and burdens, even among the living at any one time, is not automatically just. Those who suffer most from pollution are rarely, if ever, those using the most energy. Engineers still lack professional standards to guide them in the distribution of such benefits and burdens among those alive today.

Fourth, it is therefore not clear how engineers should balance the interests of those alive today against the interests of those born in the next few decades, much less those born a hundred or a thousand years from now. For example, how much, if at all, should engineers discount the interests of future generations as those generations become more likely to have interests hard to predict? Should engineers ignore the interests of those generations that might not exist at all if preceding generations destroy the resource base?

Fifth, engineers 70 years ago may have had good reason to believe that they could solve the problem of safely disposing of nuclear waste without entombing it for 10,000 years, for example, by burning the waste in thermo-nuclear reactors or rocketing it into the sun. Some options that once looked promising do not look so now.

On the other hand, one conclusion that may seem to follow from the argument made here is that today's engineers, and perhaps tomorrow's, should not build nuclear power plants until they have found a safe (and politically acceptable) way quickly to dispose of the waste such power plants generate (dispose of it, say, in three generations or less). ${ }^{9}$

Of course, drawing that conclusion is beyond the range of this commentary since (among other things) drawing that conclusion would require a detailed assessment of the alternatives to nuclear power-and that's another article, maybe even a long book, not just a few more paragraphs.

\section{References}

Davis, M. (2009). Is engineering a profession everywhere? Philosophia, 37(June), 211-225.

Davis, M. (2010a). Distinguishing architects from engineers: A pilot study in differences between engineers and other technologists. In I. van de Poel \& D. Goldberg (Eds.), Philosophy and engineering: An emerging agenda (pp. 15-30). Berlin: Springer.

\footnotetext{
9 Note that the following articles reached a similar conclusion by very different routes: Lemons et al. (1990) and Shrader-Frechette (1993).
} 
Davis, M. (2010b). Engineers and sustainability: An inquiry into the elusive distinction between Macro-, micro-, and meso-ethics. Journal of Applied Ethics and Philosophy, 2, 12-20.

Endres, D. (2009). Science and public participation: An analysis of public scientific argument in the Yucca Mountain controversy. Environmental Communication: A Journal of Nature and Culture, 3(1), 49-75.

Lemons, J., Brow, D. A., \& Varner, G. E. (1990). Congress, consistency, and environmental law: Nuclear Waste at Yucca Mountain Nevada. Environmental Ethics, 12(Winter), 311-327.

National Society of Professional Ethics. (2007). Code of ethics for engineers, http://ethics.iit.edu/ecodes/ node/4098. Accessed June 112019.

Ratliff, J. N. (1997). The politics of nuclear waste: An analysis of a public hearing on the proposed Yucca Mountain nuclear waste repository. Communication Studies, 48(4), 359-380.

Shrader-Frechette, K. S. (1993). Consent and nuclear waste disposal. Public Affairs Quarterly, 7(October), 363-377.

Wikipedia. (2019a). Izumo-taisha, https://en.wikipedia.org/wiki/Izumo-taisha. Accessed June 112019.

Wikipedia. (2019b). Onkalo spent nuclear fuel repository https://en.wikipedia.org/wiki/Onkalo_spent nuclear_fuel_repository. Accessed June 112019.

Wikipedia. (2019c). Paromeos monastery, https://en.wikipedia.org/wiki/Paromeos_Monastery. Accessed June 112019.

Wikipedia. (2019d). Yucca Mountain nuclear waste repository, https://en.wikipedia.org/wiki/Yucca _Mountain_nuclear_waste_repository. Accessed June 112019.

YuccaMountain.org. (2019). https://www.yuccamountain.org/new.htm. Accessed June 112019.

Publisher's Note Springer Nature remains neutral with regard to jurisdictional claims in published maps and institutional affiliations. 